\title{
Influence of molecular hydrogen on behavioral adaptation of Chinchilla lanigera taking into account gender factor in conditions of cage keeping
}

\author{
Elena Panina ${ }^{1}$, Alexey Ivanov $^{1}$, Dmitry Petrov ${ }^{1, *}$ and Nadezhda Panteleeva ${ }^{1}$ \\ ${ }^{1}$ Russian State Agrarian University - Moscow Timiryazev Agricultural Academy, Department of \\ Physiology, Ethology and Biochemistry of Animals, 127550 Moscow, Timiryazevskaya street, 49, \\ Russian Federaton
}

\begin{abstract}
It was found that the inclusion of water enriched with molecular hydrogen in the diet of animals increased the overall proportion of active behavior. According to the form of behavior "moving around the cage", it was found that males and females of the experimental group spent more time than animals of the control group. Males of the experimental group were $24 \%$ more active at night, and females were $60 \%$ more active than in the control group. In the daily dynamics, the period of activity of animals in the experimental group was from 19:00 to 8:00, and in the control group-from 22:00 to 8:00. In the daily balance according to the form of behavior "moving around the cage", chinchillas of the experimental group spent $5 \%$ more than in the control group.
\end{abstract}

\section{Introduction}

The long-tailed chinchilla (Chinchilla lanigera) - is a rodent native to South America. In the wild, they have almost completely disappeared, and their small colonies are preserved only in Chilean nature reserves [1]. All over the world, chinchillas are raised on farms for fur production, kept as laboratory and domestic animals [2-6]. Chinchillas are characterized by a crepuscular lifestyle, since they are most active at night [7-9]. Currently, to increase productivity and maintain animal health, antioxidants are increasingly introduced into feed - natural inhibitors of free radical oxidation [10-14]. Molecular hydrogen also belongs to such substances [15-18].

Molecular hydrogen is an antioxidant with favorable physicochemical properties for the body, is electrically neutral and has a lower molecular weight in comparison with oxygen $[19,20]$. Molecular hydrogen can easily penetrate cell membranes, the nucleus, and mitochondria [21]. In addition, molecular hydrogen does not have a negative effect on the physiological processes occurring both inside the cell and on the parameters of the body as a whole (temperature, blood pressure, $\mathrm{pH}$ ) [22].

\footnotetext{
* Corresponding author: petrov1983dmitriy@gmail.com
} 
Molecular hydrogen (H2) is an effective and non-toxic molecule, having the capacity to neutralize active oxygen species [23-26]. The biological properties of H2 were first studied in 1970 [27]. In 1975, M. Dole published an article in the journal Science that hyperbaric hydrogen therapy reduced the size of tumors in hairless mice [28]. Numerous studies have shown that molecular hydrogen has an effect in the treatment of neurological diseases, including brain damage, Alzheimer's disease, Parkinson's disease, and so on [29-32]. Studies conducted by K. Nagata confirmed that copious consumption of molecular hydrogen-rich water (HRW) reduced oxidative stress in the brain and prevented induced stress in mice caused by physical isolation of animals [33].

Molecular hydrogen can be introduced in various ways: inhaling $\mathrm{H} 2$; with water; enriched with molecular hydrogen; taking molecular hydrogen baths; using eye drops with molecular hydrogen [34-38]. Enriching the body with H2 increases the concentration of the hydrogen antioxidant in the blood [39]. Sometimes reception HRW can have more effecting result than inhalation of $\mathrm{H} 2$, although the concentration of molecular hydrogen in water is less than when inhaled [40-42]. Saturation HRW molecular hydrogen reaches a peak concentration of 5 - 15 minutes and returned to baseline values at the expiration of $45-90$ minutes after reception [43]. Excess molecular hydrogen is eliminated from the body through the lungs [44]. Taking into account the numerous advantages of molecular hydrogen, it is worth noting that it is also a radio protective agent [45-48]. In the ethological aspect, the effect of HRW has not been studied, therefore, the purpose of our work was to identify the effect of HRW on the behavioral adaptation of the long-tailed chinchilla in conditions of cage keeping.

\section{Materials and methods}

For the ethological study, ten pairs of clinically healthy male and female Chinchilla lanigera two months of age with an average weight of 268 grams were selected. The animals were housed in pairs in separate cages at a constant temperature $\left(19 \pm 2{ }^{\circ} \mathrm{C}\right)$ with 12-hour day/night cycles and free access to food and water. Feeding was carried out in plenty of granulated compound feed for chinchillas.

Wooden blocks were placed in each cage for grinding the incisors. Watering of both groups of animals was carried out by an automatic watering system with the only difference that an apparatus for generating HRW "Lourdes HS-81" was connected to the automatic watering system of the experimental group. The concentration of molecular hydrogen at the outlet of the nipple drinkers of the experimental group was 0.1-1.1 ppm, depending on the operating mode of the apparatus. The apparatus for generating $\mathrm{H} 2$ was turned on twice a day (H2 generation mode) in the morning and in the evening for 30 minutes, until the timer turned off, the rest of the time it worked in standby mode.

After 10 months of keeping in the experimental conditions, an ethological study was carried out by the method of remote observation for 24 hours using a video system with four infrared cameras, which made it possible to conduct remote observation of the behavior of animals during the day, including day and night. It is important to note that this research method excluded the presence of an observer. When observing chinchillas, the application "Multitimer" version 2.6.1.217 was used. The digital material was processed by the method of variation statistics using the MsExcel program. To identify statistically significant differences, the Student-Fisher test was used. 


\section{Results and discussion}

Studies have shown that the inclusion of water enriched with molecular hydrogen with a hydrogen concentration of 0.1-1.1 ppm in the diet of a small long-tailed chinchilla under cage conditions influenced various forms of animal behavior during the day. For inactive forms of behavior, such as sleep, naps, rest, it was found that in the small long-tailed chinchilla, males and females of the control group spent an average of 57 minutes for sleep at night, and in the experimental group it was 40\% less (23 minutes) (Table 2) The animals slept in the daytime on average $85 \%$ longer than at night (Table 2). In terms of sleep duration, the peak was recorded in males in the control group at 12 noon and was 46 minutes per pattern, and in males in the experimental group - at 13 hours (46 minutes). In the females of the experimental group, the peak in sleep duration was recorded at 13 hours and amounted to 41 minutes, and in the control group in females, the maximum sleep duration fell on 16 hours (40 minutes). The chinchillas of the control group spent $23 \%$ of the daily time for sleep, and $20 \%$ of the daily time in the experimental group (Fig. 11). On a nap in both groups, the animals spent an average of 159 minutes in the daytime and at night (Table 1,2). In daily dynamics, the peak of this indicator in both groups fell at night (20:00) and was 28 minutes in males in the control group, and 42 minutes in the experimental group, and 43 minutes in females in the control and experimental groups. In the daily balance, naps in both groups in males accounted for $20 \%$ of the daily time in females $-24 \%$ (Fig. 11). For rest, the males of both groups spent $15 \%$ of the daytime (Fig. 5) and $37 \%$ of the night time (Fig. 7). The maximum value in the control group was recorded at 1 hour and was 41 minutes, and in the experimental group at 24 hours - 33 minutes. Females of the control group spent 2 hours 28 minutes on rest during the daytime, and in the experimental group they spent $19 \%$ less daytime (Table 1).

By active forms of behavior (feeding, autocoprophagia, grooming, grooming a partner, taking water, moving around the cage, gnawing a wooden block, gnawing a cage net, gnawing a wooden shelf, taking a bolus, communicating with each other, stretching, scratching, communicating with chinchillas of a neighboring cells) in males of the control group in the daily balance accounted for $30 \%$, and in males in the experimental group $33 \%$ of the time (Fig. 9). In females of the control group, this indicator was $21 \%$, and in the experimental group - $31 \%$ of the daily time (Fig. 10). The males of the control group spent 436 minutes on active behavior per day, while in the experimental group they spent $10 \%$ more time. In females, active behavior in the control group spent 298 minutes of the daily time, and in the experimental group it took $33 \%$ more daily time $(\mathrm{p}<0.05)$ (Table 3$)$.

The males of the experimental group spent $55 \%$ more time on moving around the cage in the daytime than the males of the control group - 24 minutes, and in the females of the experimental group this indicator was $59 \%$ higher than that of the females of the control group - 14 minutes. On average, during the day in the control group, the animals moved around the cage for 19 minutes from daytime, and in the experimental group, they moved $56 \%$ more $(\mathrm{p}<0.05)$ (Table 1$)$. At night, there was an increase in activity according to this indicator in the control group by $77 \%$, and in the experimental group - by $67 \%$ compared with the daytime (Table 2). The males of the experimental group were $24 \%$ more active than the males of the control group at night, and the females were $60 \%$ more active than the females of the control group (40 minutes) (Table 2). In the diurnal dynamics, the period of activity of animals in the experimental group fell from 19:00 to 08:00 (on average 12 minutes), and in the control group from 22:00 to 8:00 (on average 6 minutes). In males in the control group, the maximum value was detected at 23:00 and amounted to 21 minutes per pattern. In the experimental group, the peak was recorded at 1 hour (21 minutes) (Fig. 3 ). In the diurnal dynamics of the behavior of females in the control group, according to this indicator, the peak of activity was recorded at 2 hours and amounted to 6 minutes; in 
the experimental group, the maximum value was detected at 22 hours (18 minutes) (Fig. 4). In the daily balance according to the form of behavior "moving around the cage", the males of the experimental group spent $15 \%$ of the time, which is $5 \%$ more than in the control (Fig. 9). Females of the experimental group spent $9 \%$ of the time in the daily balance according to the form of behavior "moving around the cage", which is $5 \%$ more than in the control group (4\% of the daily time) (Fig. 10).

Table 1. Monitoring of chinchilla behavior during the day, minutes.

\begin{tabular}{|c|c|c|c|c|c|c|}
\hline \multirow{3}{*}{ indicator } & \multicolumn{6}{|c|}{ group } \\
\hline & \multicolumn{3}{|c|}{ control } & \multicolumn{3}{|c|}{ experimental } \\
\hline & males & females & overall & males & females & overall \\
\hline sleep & $280 \pm 24.0$ & $268 \pm 33.7$ & $274 \pm 19.6$ & $276 \pm 20.3$ & $253 \pm 15.1$ & $264 \pm 12.5$ \\
\hline nap & $175 \pm 15.1$ & $185 \pm 14.7$ & $180 \pm 10.1$ & $160 \pm 10.9$ & $163 \pm 41.3$ & $161 \pm 20.1$ \\
\hline rest & $113 \pm 14.6$ & $148 \pm 37.6$ & $131 \pm 19.9$ & $111 \pm 9.6$ & $121 \pm 20.4$ & $116 \pm 10.8$ \\
\hline $\begin{array}{c}\text { general inactive } \\
\text { behavior }\end{array}$ & $568 \pm 20.0$ & $601 \pm 16.2$ & $584 \pm 13.3$ & $546 \pm 14.6$ & $536 \pm 32.5$ & $541 \pm 16.9$ \\
\hline $\begin{array}{l}\text { nibbling the cage } \\
\text { mesh }\end{array}$ & $6.4 \pm 1.46$ & $8,2 \pm 2.83$ & $7.3 \pm 1.53$ & $8.3 \pm 1.73$ & $17.3 \pm 4.86$ & $12.8 \pm 2.85$ \\
\hline feed intake & $30.6 \pm 5.44$ & $25.5 \pm 4.07$ & $28.0 \pm 3.31$ & $23.7 \pm 4.29$ & $32.5 \pm 4.33$ & $28.1 \pm 3.23$ \\
\hline autocoprophagia & $47.0 \pm 9.73$ & $43.2 \pm 10.35$ & $45.1 \pm 6.72$ & $44.0 \pm 12.92$ & $46.0 \pm 9.24$ & $45.0 \pm 7.49$ \\
\hline water intake & $2.9 \pm 0.52$ & $3.2 \pm 1.11$ & $3.0 \pm 0.58$ & $2.0 \pm 0.46$ & $5.5 \pm 3.27$ & $3.8 \pm 1.66$ \\
\hline grooming partner & $3.4 \pm 1.32$ & $1.8 \pm 0.72$ & $2.6 \pm 0.76$ & $5.8 \pm 2.81$ & $8.9 \pm 3.39$ & $7.3 \pm 2.14$ \\
\hline grooming & $21.9 \pm 2.05$ & $16.4 \pm 3.68$ & $19.2 \pm 2.19$ & $27.7 \pm 4.46$ & $18.9 \pm 5.15$ & $23.3 \pm 3.53$ \\
\hline $\begin{array}{l}\text { moving around } \\
\text { the cage }\end{array}$ & $23.6 \pm 4.03$ & $13.5 \pm 2.40$ & $18.5 \pm 2.78^{*}$ & $52.5 \pm 15.06$ & $32.6 \pm 10.07$ & $42.6 \pm 9.16^{*}$ \\
\hline $\begin{array}{l}\text { gnawing on a } \\
\text { wooden shelf }\end{array}$ & $10.5 \pm 5.75$ & $2.2 \pm 1.42$ & $6.3 \pm 3.12$ & $2.7 \pm 1.12$ & $2.6 \pm 2.41$ & $2.7 \pm 1.25$ \\
\hline $\begin{array}{l}\text { communication } \\
\text { with each other }\end{array}$ & $0.1 \pm 0.09$ & $0.1 \pm 0.10$ & $0.1 \pm 0.06$ & $0.5 \pm 0.18$ & $2.7 \pm 2.39$ & $1.6 \pm 1.19$ \\
\hline sipping & $0.6 \pm 0.21$ & $0.3 \pm 0.13$ & $0.5 \pm 0.12$ & $0.6 \pm 0.19$ & $2.7 \pm 2.24$ & $1.6 \pm 1.12$ \\
\hline scratching & $2.2 \pm 0.53$ & $1.9 \pm 0.37$ & $2.1 \pm 0.31$ & $2.7 \pm 0.72$ & $4.8 \pm 2.67$ & $3.8 \pm 1.35$ \\
\hline $\begin{array}{c}\text { gnawing a block } \\
\text { of wood }\end{array}$ & $1.1 \pm 0.69$ & $2.1 \pm 2.03$ & $1.6 \pm 1.02$ & $2.3 \pm 0.58$ & $6.0 \pm 2.56$ & $4.2 \pm 1.38$ \\
\hline $\begin{array}{l}\text { communication } \\
\text { with the } \\
\text { chinchillas of the } \\
\text { neighboring cage }\end{array}$ & $1.6 \pm 0.80$ & $0.7 \pm 0.28$ & $1.1 \pm 0.42$ & $1.1 \pm 0.48$ & $3.2 \pm 2.11$ & $2.2 \pm 1.08$ \\
\hline $\begin{array}{c}\text { general active } \\
\text { behavior }\end{array}$ & $152 \pm 20.0$ & $119 \pm 16.2$ & $136 \pm 13.3$ & $174 \pm 14.6$ & $184 \pm 32.4$ & $179 \pm 16.8$ \\
\hline
\end{tabular}

Note: here and below * - the difference between the control and experimental group with a reliability of $\mathrm{p}<0.05$

According to the feeding behavior, which included such forms as food intake, water intake and autocoprophagia, it was found that throughout the entire time the animals periodically showed this type of activity. The maximum value in animals of both groups was recorded at 9:00, but in the experimental group the feeding behavior was longer and amounted to 16 minutes, which is 3.2 minutes more than in the control.

According to the form of "food intake" behavior, feeding activity in Chinchilla lanigera was observed throughout the entire daily time, while the maximum value in males in the experimental group was at 06:00 and was 9 minutes, and in the control group at 15:00 (8 
minutes). Females were most active in food intake in the experimental group at 05:00 (9 minutes), and in the control group at 06:00 (7 minutes). During the daytime, the animals spent an average of 28 minutes on food consumption (Table 1). At night, males spent 45 minutes on food intake in the control group, and $6 \%$ more in the experimental group. For females, taking food at night in the control group was 53 minutes, and in the experimental group it was $15 \%$ longer. During the day, chinchillas in the experimental group spent 83 minutes on food intake, and $6 \%$ less in the control group (Table 3).

Table 2. Monitoring of chinchilla behavior during the night, minutes.

\begin{tabular}{|c|c|c|c|c|c|c|}
\hline \multirow{3}{*}{ indicator } & \multicolumn{6}{|c|}{ group } \\
\hline & \multicolumn{3}{|c|}{ control } & \multicolumn{3}{|c|}{ experimental } \\
\hline & males & females & overall & males & females & overall \\
\hline sleep & $47.3 \pm 20.04$ & $66.1 \pm 24.54$ & $56.7 \pm 15.26$ & $18.1 \pm 5.73$ & $28.9 \pm 10.07$ & $23.5 \pm 5.75$ \\
\hline nap & $118 \pm 22.6$ & $161 \pm 26.9$ & $139 \pm 18.0$ & $125 \pm 13.4$ & $187 \pm 39.3$ & $156 \pm 22.1$ \\
\hline rest & $273 \pm 53.6$ & $317 \pm 42.8$ & $295 \pm 33.1$ & $270 \pm 43.2$ & $247 \pm 18.4$ & $259 \pm 22.5$ \\
\hline general inactive behavior & $438 \pm 48.1$ & $543 \pm 21.7$ & $491 \pm 30.4$ & $414 \pm 42.8$ & $463 \pm 32.8$ & $438 \pm 26.7$ \\
\hline nibbling the cage mesh & $38.5 \pm 15.31$ & $14.2 \pm 1.97$ & $26.3 \pm 8.33$ & $13.7 \pm 4.74$ & $16.1 \pm 4.89$ & $14.9 \pm 3.24$ \\
\hline feed intake & $44.8 \pm 8.38$ & $53.0 \pm 6.70$ & $48.9 \pm 5.24$ & $48.2 \pm 6.49$ & $61.5 \pm 2.90$ & $54.8 \pm 4.01$ \\
\hline autocoprophagia & $6.2 \pm 1.59$ & $7.3 \pm 3.77$ & $6.8 \pm 1.94 *$ & $1.9 \pm 0.72$ & $2.1 \pm 1.06$ & $2.0 \pm 0.60 *$ \\
\hline water intake & $6.3 \pm 1.34$ & $7.4 \pm 0.67$ & $6.8 \pm 0.73$ & $5.9 \pm 0.83$ & $6.3 \pm 0.54$ & $6.1 \pm 0.47$ \\
\hline grooming partner & $4.2 \pm 0.69$ & $5.4 \pm 1.21$ & $4.8 \pm 0.69$ & $3.3 \pm 0.92$ & $7.9 \pm 2.35$ & $5.6 \pm 1.41$ \\
\hline grooming & $21.3 \pm 3.41$ & $17.1 \pm 3.01$ & $19.2 \pm 2.25$ & $31.2 \pm 13.73$ & $20.4 \pm 2.45$ & $25.8 \pm 6.82$ \\
\hline moving around the cage & $121 \pm 32.8$ & $40.2 \pm 12.31$ & $80.4 \pm 21.27$ & $158 \pm 36.3$ & $99.9 \pm 31.49$ & $129 \pm 24.6$ \\
\hline $\begin{array}{l}\text { gnawing on a wooden } \\
\text { shelf }\end{array}$ & $13.4 \pm 5.77$ & $3.5 \pm 3.21$ & $8.5 \pm 3.52$ & $3.7 \pm 3.05$ & $2.5 \pm 2.15$ & $3.1 \pm 1.77$ \\
\hline $\begin{array}{l}\text { communication with each } \\
\text { other }\end{array}$ & $0.6 \pm 0.50$ & $0.3 \pm 0.25$ & $0.4 \pm 0.27$ & $0.4 \pm 0.17$ & $0.9 \pm 0.43$ & $0.6 \pm 0.24$ \\
\hline sipping & $0.1 \pm 0.09$ & $0.2 \pm 0.08$ & $0.2 \pm 0.06$ & $0.2 \pm 0.08$ & $0.2 \pm 0.09$ & $0.2 \pm 0.06$ \\
\hline scratching & $1.8 \pm 0.32$ & $1.3 \pm 0.14$ & $1.5 \pm 0.18$ & $2.1 \pm 0.57$ & $1.5 \pm 0.32$ & $1.8 \pm 0.32$ \\
\hline gnawing a block of wood & $23.0 \pm 6.28$ & $26.7 \pm 17.17$ & $24.8 \pm 8.64$ & $36.5 \pm 13.96$ & $36.7 \pm 13.89$ & $36.6 \pm 9.28$ \\
\hline $\begin{array}{l}\text { communication with the } \\
\text { chinchillas of the } \\
\text { neighboring cage }\end{array}$ & $1.0 \pm 0.39$ & $0.3 \pm 0.26$ & $0.6 \pm 0.25$ & $1.6 \pm 0.69$ & $1.0 \pm 0.92$ & $1.3 \pm 0.55$ \\
\hline general active behavior & $282 \pm 48.1$ & $177 \pm 21.7$ & $229 \pm 30.4$ & $307 \pm 42.8$ & $257 \pm 32.8$ & $282 \pm 26.7$ \\
\hline
\end{tabular}

According to the form of "water intake" behavior, food activity in chinchillas was observed throughout the entire daily time, while in males the maximum duration of water consumption was 1 minute and in the experimental group it was at 23:00, and in the control group - 06:00. In terms of water consumption, the females showed the greatest activity at 06:00 and in terms of duration in the experimental group it was 1 minute, and in the control group - 2 minutes. In the daytime, the animals spent an average of 3 minutes for drinking (Table 1), and at night for 6 minutes (Table 2). In the daily balance, Chinchilla lanigera spent $1 \%$ of the time on water intake (Fig. 11).

According to the form of "autocoprophagia" behavior, activity in the diurnal dynamics is observed from 08:00 to 19:00 hours, while in males the maximum duration of bolus eating falls at 09:00 on average for 11-12 minutes. In females, the feeding activity of eating 
a bolus is manifested from 07:00 to 19:00, while the peak of activity is observed in the control group at 08:00 and is 8 minutes per pattern, and in the experimental group - 09:00 (15 minutes). During the daytime, animals spend an average of $6 \%$ of the time on bolus consumption (Fig. 5, 6). At night, the Chinchilla lanigera of the control group spent an average of 7 minutes on bolus consumption, and in the experimental group it spent $71 \%$ less time $(\mathrm{p}<0.05)$ (Table 2$)$. In the daily balance, Chinchilla lanigera spent $4 \%$ of the time on receiving a bolus in the control group, and 3\% in the experimental group (Fig. 11).

Table 3. Monitoring the behavior of chinchillas during the daily time, minutes.

\begin{tabular}{|c|c|c|c|c|c|c|}
\hline \multirow{3}{*}{ indicator } & \multicolumn{6}{|c|}{ group } \\
\hline & \multicolumn{3}{|c|}{ control } & \multicolumn{3}{|c|}{ experimental } \\
\hline & males & females & overall & males & females & overall \\
\hline sleep & $328 \pm 27.7$ & $334 \pm 50.5$ & $331 \pm 27.2$ & $295 \pm 23.4$ & $282 \pm 14.5$ & $289 \pm 13.1$ \\
\hline nap & $293 \pm 30.9$ & $347 \pm 35.2$ & $320 \pm 23.9$ & $285 \pm 22.5$ & $350 \pm 46.1$ & $317 \pm 26.5$ \\
\hline rest & $384 \pm 54.6$ & $461 \pm 76.8$ & $422 \pm 46.3$ & $378 \pm 49.3$ & $366 \pm 19.0$ & $372 \pm 26.0$ \\
\hline $\begin{array}{c}\text { general inactive } \\
\text { behavior }\end{array}$ & $1004 \pm 44.3$ & $1142 \pm 27 *$ & $1073 \pm 34^{*}$ & $958 \pm 34.3$ & $997 \pm 21.2^{*}$ & $978 \pm 20^{*}$ \\
\hline nibbling the cage mesh & $45.0 \pm 15.53$ & $22.5 \pm 4.46$ & $33.8 \pm 8.49$ & $22.2 \pm 5.58$ & $33.6 \pm 7.25$ & $27.9 \pm 4.72$ \\
\hline feed intake & $76.3 \pm 12.10$ & $78.7 \pm 9.43$ & $77.5 \pm 7.25$ & $72.0 \pm 6.29$ & $94.1 \pm 3.32$ & $83.0 \pm 4.98$ \\
\hline autocoprophagia & $53.4 \pm 11.27$ & $50.6 \pm 10.0$ & $52.0 \pm 7.12$ & $46 \pm 13.3$ & $49 \pm 10.1$ & $47.4 \pm 7.90$ \\
\hline water intake & $9.3 \pm 1.20$ & $10.7 \pm 1.46$ & $10.0 \pm 0.92$ & $8.1 \pm 1.27$ & $12.0 \pm 3.21$ & $10.0 \pm 1.75$ \\
\hline grooming partner & $7.7 \pm 1.84$ & $7.4 \pm 1.89$ & $7.6 \pm 1.25$ & $9.1 \pm 3.10$ & $16.9 \pm 4.60$ & $13.0 \pm 2.91$ \\
\hline grooming & $43.2 \pm 2.57$ & $33.7 \pm 2.26$ & $38.5 \pm 2.26$ & $59 \pm 16.5$ & $39.4 \pm 7.07$ & $49.2 \pm 9.07$ \\
\hline moving around the cage & $144 \pm 34.9$ & $54 \pm 14.0$ & $99.0 \pm 23.3$ & $210 \pm 40.5$ & $133 \pm 40.2$ & $172 \pm 29.8$ \\
\hline $\begin{array}{l}\text { gnawing on a wooden } \\
\text { shelf }\end{array}$ & $24.1 \pm 10.13$ & $5.9 \pm 3.38$ & $15.0 \pm 5.88$ & $6.6 \pm 2.76$ & $5.3 \pm 2.67$ & $5.9 \pm 1.82$ \\
\hline $\begin{array}{c}\text { communication with } \\
\text { each other }\end{array}$ & $0.9 \pm 0.46$ & $0.6 \pm 0.25$ & $0.7 \pm 0.25$ & $1.1 \pm 0.43$ & $3.8 \pm 2.15$ & $2.4 \pm 1.13$ \\
\hline sipping & $0.9 \pm 0.29$ & $0.7 \pm 0.21$ & $0.8 \pm 0.17$ & $0.9 \pm 0.32$ & $3.0 \pm 2.18$ & $2.0 \pm 1.09$ \\
\hline scratching & $4.1 \pm 0.58$ & $3.4 \pm 0.29$ & $3.8 \pm 0.33$ & $4.8 \pm 0.80$ & $6.4 \pm 2.61$ & $5.6 \pm 1.32$ \\
\hline $\begin{array}{l}\text { gnawing a block of } \\
\text { wood }\end{array}$ & $24.3 \pm 6.59$ & $29 \pm 18.8$ & $27 \pm 9.4$ & $39 \pm 14.2$ & $42.8 \pm 14.32$ & $40.9 \pm 9.53$ \\
\hline $\begin{array}{l}\text { communication with the } \\
\text { chinchillas of the } \\
\text { neighboring cage }\end{array}$ & $2.8 \pm 1.03$ & $1.1 \pm 0.43$ & $2.0 \pm 0.59$ & $2.8 \pm 1.17$ & $4.4 \pm 2.16$ & $3.6 \pm 1.19$ \\
\hline general active behavior & $436 \pm 44.3$ & $298 \pm 26.7^{*}$ & $367 \pm 33.5^{*}$ & $482 \pm 34.3$ & $443 \pm 21.2^{*}$ & $462 \pm 20.1 *$ \\
\hline
\end{tabular}

According to the form of behavior "gnawing the cage net", it was revealed that males in the control group spent $3 \%$ of the daily time, in the experimental group - $2 \%$ (Fig. 9), and in females in both groups, $2 \%$ each (Fig. 10). In males of the control group, on average, it took 6 minutes of daytime to gnaw at the cage mesh, while in males in the experimental group it took $23 \%$ more (Table 1). Females of the control group spent 8 minutes of daytime according to this indicator, and in the experimental group it was 53\% more (Table 1). At night, the activity in this form of behavior in comparison with the daytime in the control group increases, in males by $83 \%$, in females by $42 \%$ of the time (Table 2 ). In the experimental group, this indicator in males increases by $39 \%$ of the time, and in females it decreases by $7 \%$ (Table 2). In the diurnal dynamics of the behavior of males, there is a peak 
in the activity of gnawing the cage mesh in the control group at 22:00 (7 minutes), and in the experimental group at 05:00 (3 minutes). In the diurnal dynamics of the behavior of females according to this indicator, the peak of activity was recorded in the control group at 22:00 and was 4 minutes in duration, and in the experimental group at 05:00 (3 minutes) and at 07:00 (3 minutes).

According to the form of behavior "gnawing a wooden block", it was observed that in the control group, males and females spent $2 \%$ of the daily time, in the experimental group - 3\% (Fig. 9, 10). In the control group, on average, males spent $95 \%$ more time on gnawing a wooden block at night than in the daytime, and females more by $92 \%$ (Tables 1,2$)$. In the experimental group, males and females gnawed a wooden block for an average of 37 minutes at night, and in the daytime, males - 2 minutes (94\% less than at night), females - 6 minutes (84\% less than at night) (Tables 1,2). In the diurnal dynamics for this form of behavior in males of both groups, the peak of activity is observed at 01:00 and is 5 minutes in the control group and 8 minutes in the experimental group. In females, in the diurnal dynamics of behavior, the peak of activity occurs in the control group at 01:00 and is 11 minutes in duration, and in the experimental group at 02:00 (10 minutes).

According to the form of behavior "gnawing a wooden shelf", it was revealed that in the experimental group, males and females spent on average 6 minutes of their daily time, in the control group - 15 minutes (Table 3). In the diurnal dynamics of the behavior of males to gnaw a wooden shelf, the maximum value was recorded in the control group at 09:00 (7 minutes), and in the experimental group at 07:00 (2 minutes). In females, in the diurnal dynamics of behavior according to this indicator, the peak of activity was observed in both groups at 07:00 and was 2 minutes in duration.

According to the form of grooming behavior, it was found that males in the control group spent an average of 3\% of the daily time, and in the experimental group - $4 \%$ (Fig. 9). Females of the control group spent $2 \%$ of the daily time for grooming, and in the experimental group - 3\% (Fig. 10). In the daytime, males in the control group spent 22 minutes, and in the experimental group - $21 \%$ more. In females in the daytime in the control group, the activity was 16 minutes, and in the experimental group - $13 \%$ more (Table 1). At night, males in the control group spent 21 minutes, and in the experimental group - $22 \%$ more. In females, the total time for this indicator in the control group was 17 minutes, which is $16 \%$ less than in the experimental group. In the diurnal dynamics of the behavior of chinchillas, grooming was observed throughout the entire time. In males of the control group, the peak of activity was recorded at 14:00 and was 6 minutes, in the experimental group, the maximum value was observed at 9:00 (8 minutes). Females of the control group showed the maximum grooming activity at 9:00 (3 minutes), and in the experimental group - at 6:00 (3 minutes).

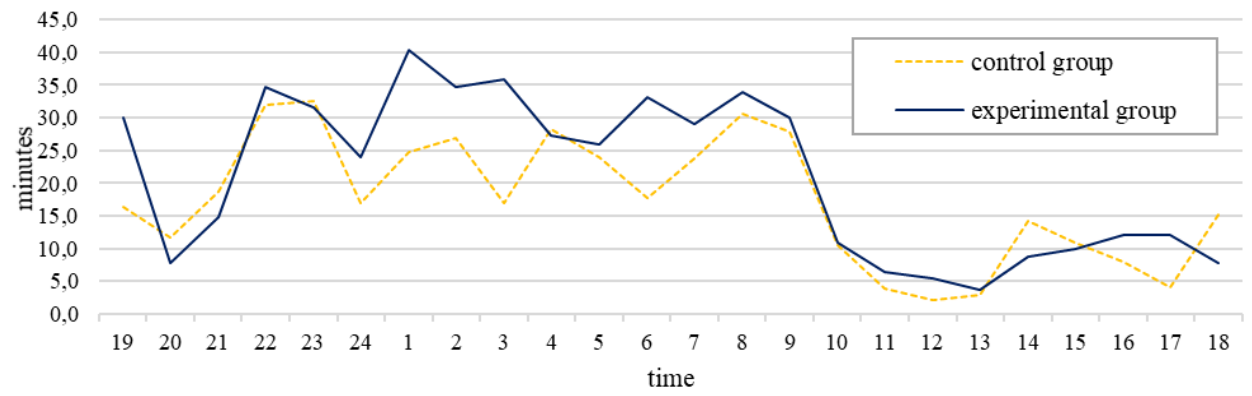

Fig. 1 Diurnal dynamics of active behavior of long-tailed chinchilla males. 


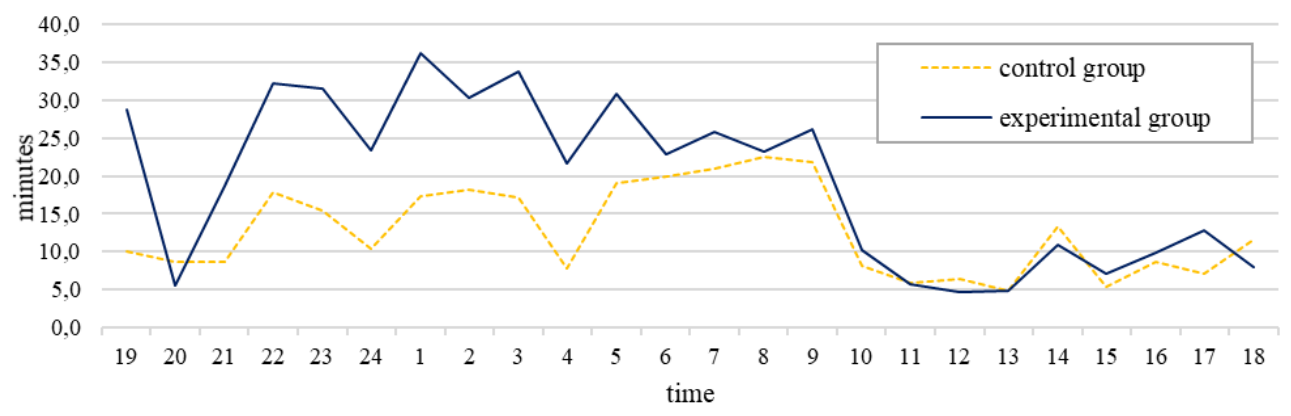

Fig. 2 Diurnal dynamics of active behavior of females of the long-tailed chinchilla.

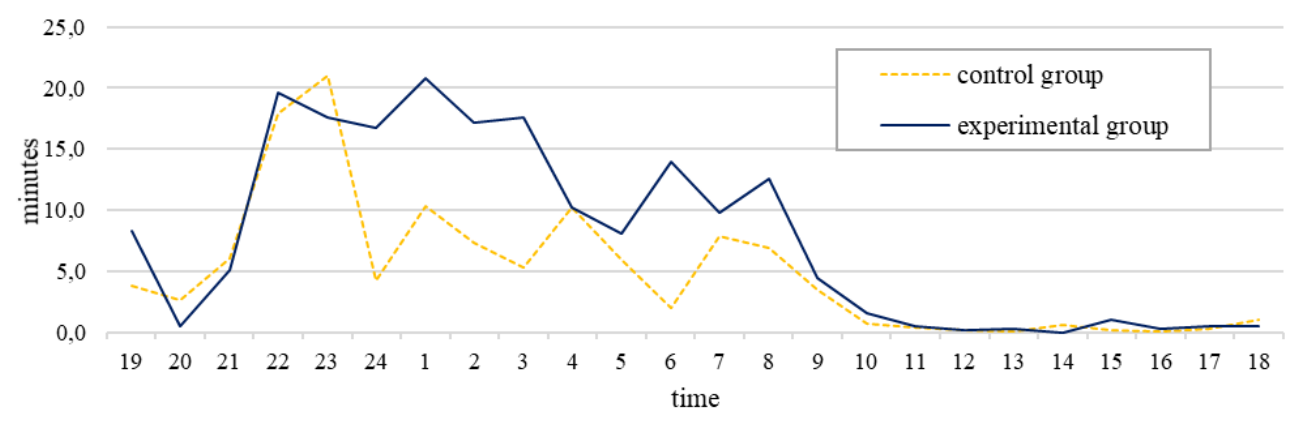

Fig. 3 Diurnal dynamics of long-tailed chinchilla males in terms of behaviour "moving around the cage".

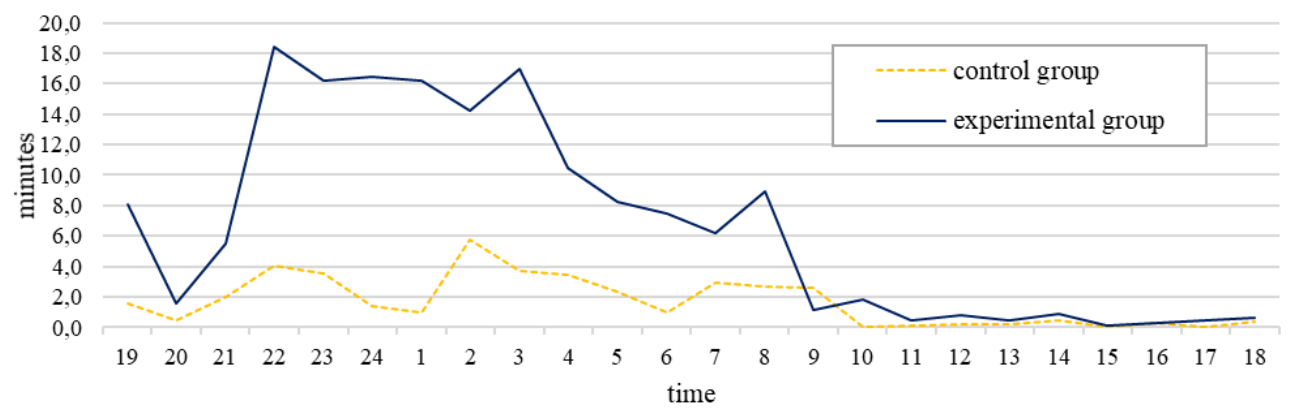

Fig. 4 Diurnal dynamics of long-tailed chinchilla females in terms of behaviour "moving around the cage"

According to the form of "grooming partner" behavior, males and females of the control group spent on average 8 minutes of daily time, while in the experimental group, males spent $16 \%$ more daily time, females - $45 \%$ more. In the diurnal dynamics of behavior in animals according to this indicator, the activity was manifested throughout the entire diurnal time. The maximum value in males in the control group was observed at 5:00 and was 1 minute. In the experimental group, the peak of activity was recorded at 8:00 (2 minutes). In females in the control group, the peak was observed at 5:00 (2 minutes), and in the experimental group, at 1:00 (3 minutes).

For such active forms of behavior as gnawing a wooden block, gnawing a wooden shelf, communicating with each other, stretching, scratching, communicating with chinchillas of a neighboring cage, both groups accounted for $3-4 \%$ of the daily time on average (Fig. 11). 
According to these forms of behavior, no significant differences were found between the groups.
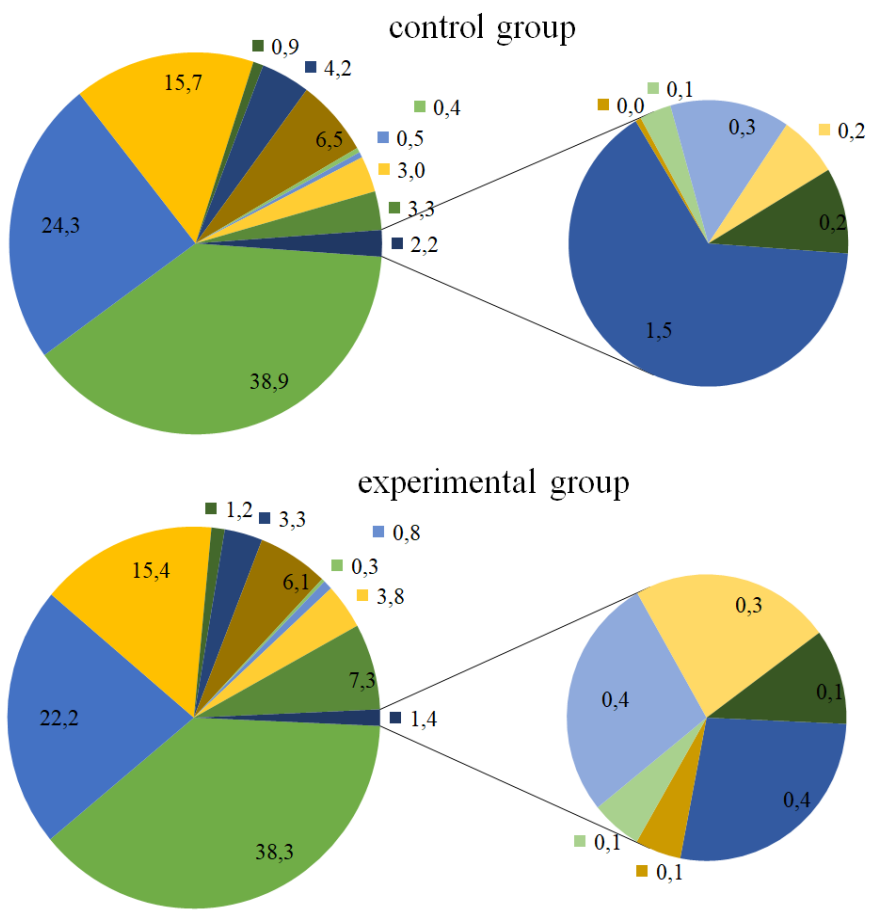

Fig. 5 Behavior of long-tailed chinchilla males in the daytime, \%.
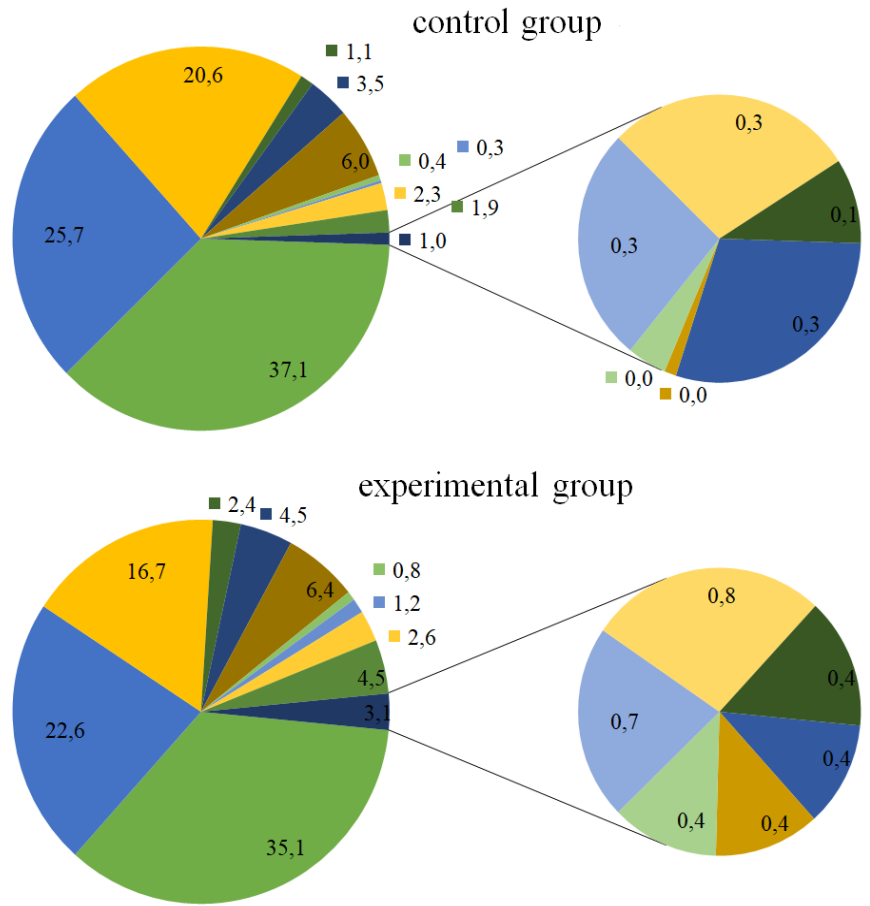

Fig. 6 Behavior of females of long-tailed chinchilla in the daytime, \%

\section{- sleep}

nap

rest

- nibbling the cage mesh

- feed intake

- autocoprophagia

water intake

m grooming partner

grooming

moving around the cage

- gnawing on a wooden shelf

- communication with each other

घipping

Inscratching

gnawing a block of wood

- communication with the chinchillas of the neighboring cage घleep

nap

rest

nibbling the cage mesh

- feed intake

n autocoprophagia

water intake

grooming partner

घrooming

moving around the cage

- gnawing on a wooden shelf

- communication with each other

- sipping

घscratching

gnawing a block of wood

- communication with the chinchillas of the neighboring cage 


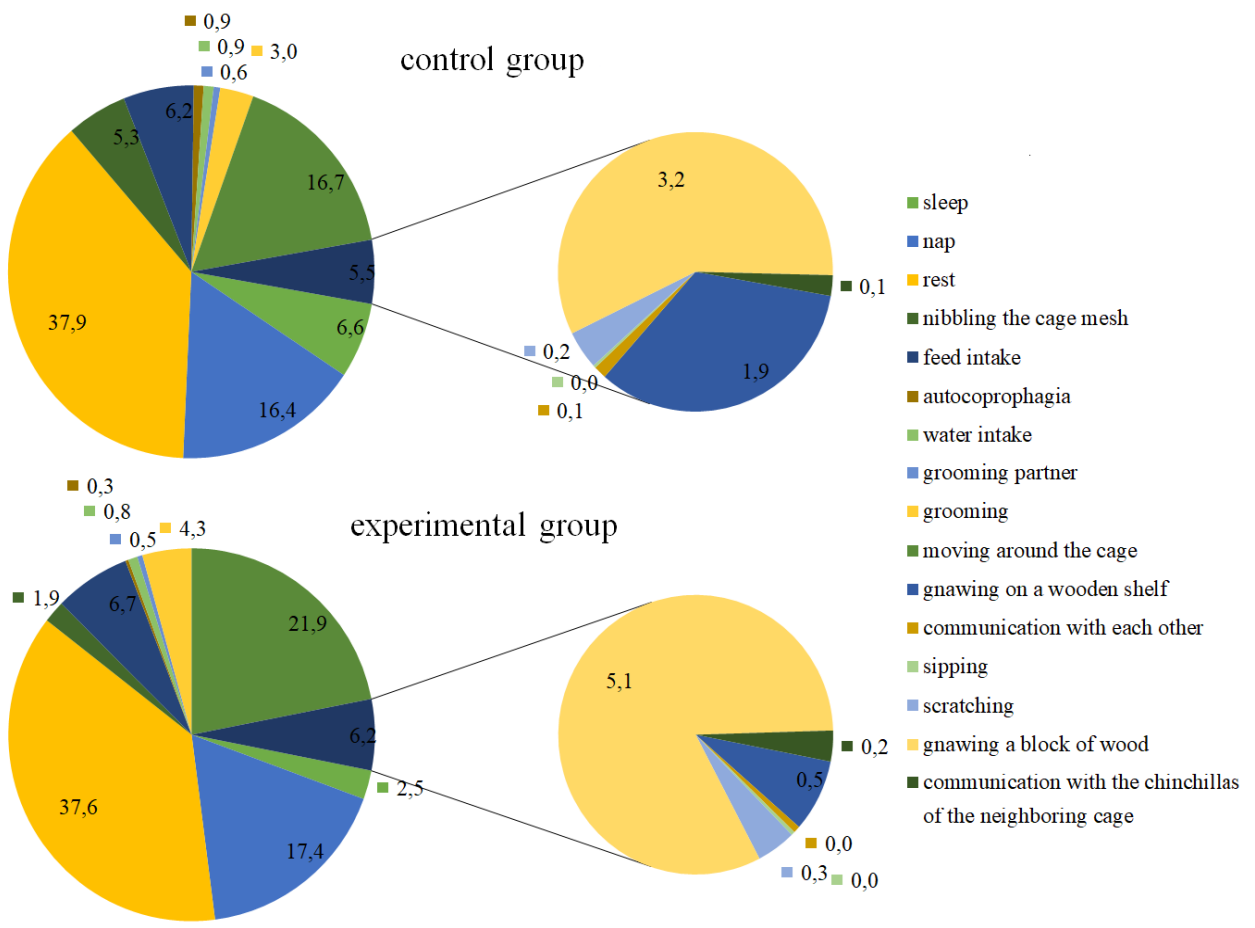

Fig. 7 Behavior of long-tailed chinchilla males at night, \%.

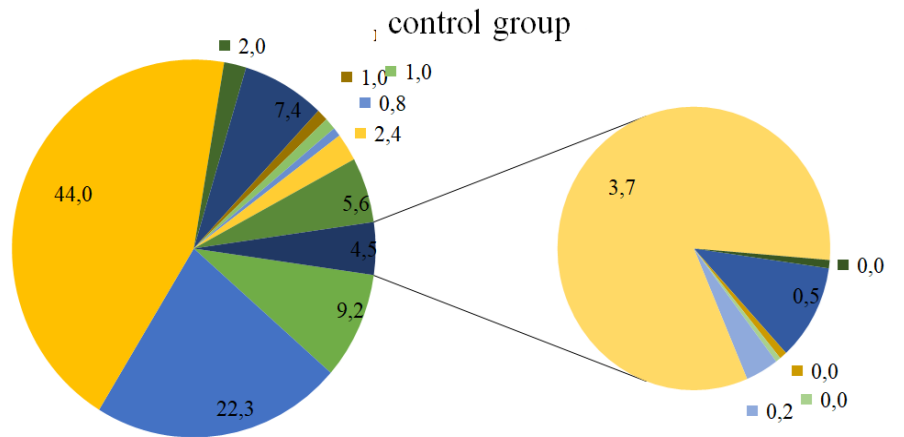

sleep

nap

rest

nibbling the cage mesh

- feed intake

n autocoprophagia

water intake

- grooming partner

grooming

moving around the cage

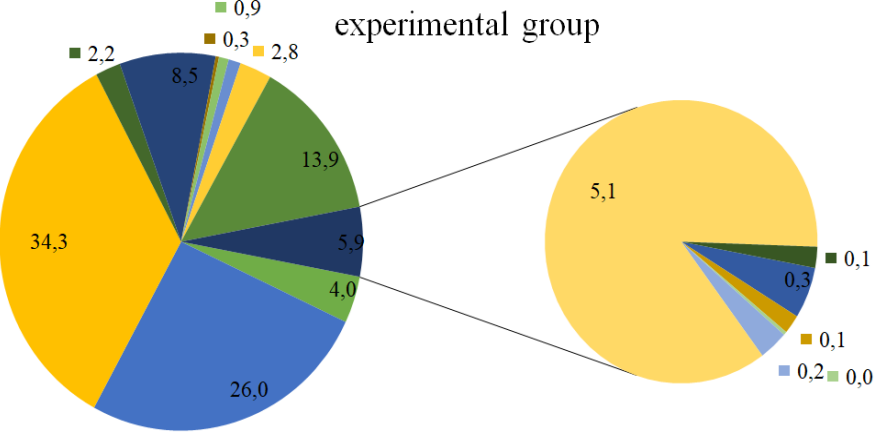

- gnawing on a wooden shelf

v communication with each other

wipping

- scratching

gnawing a block of wood

a communication with the chinchillas of the neighboring cage

Fig. 8 Behavior of long-tailed chinchilla females at night, \% 

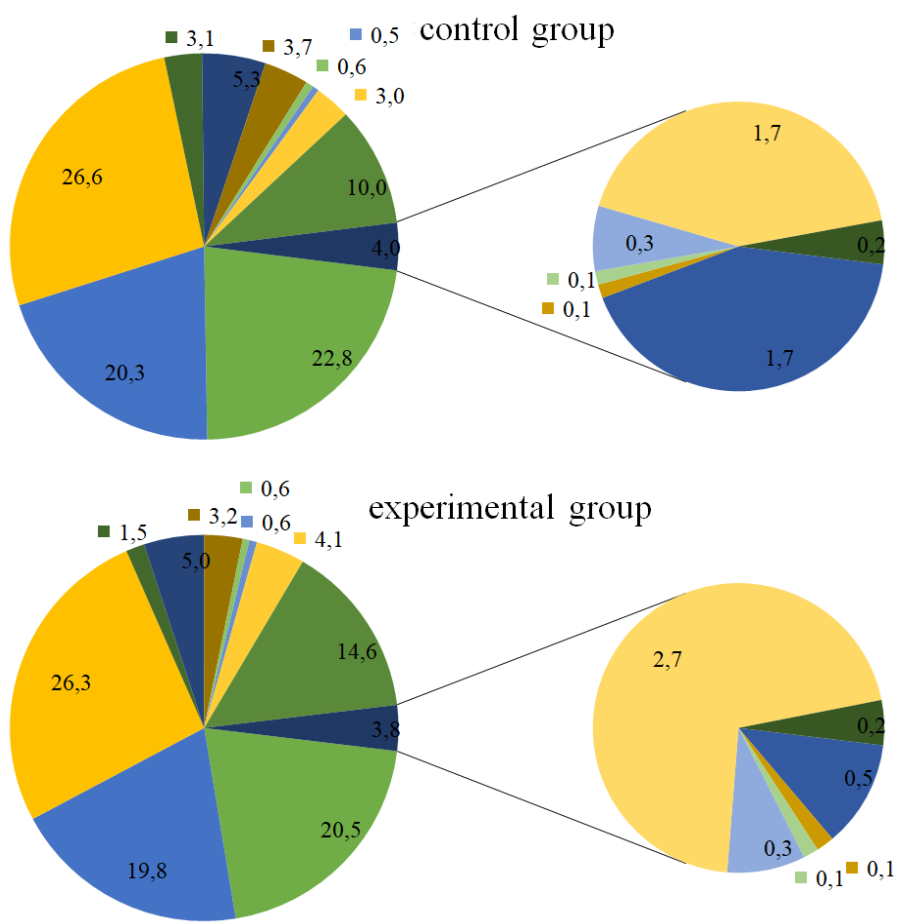

Fig. 9 Behavior of long-tailed chinchilla males during the day, \%.
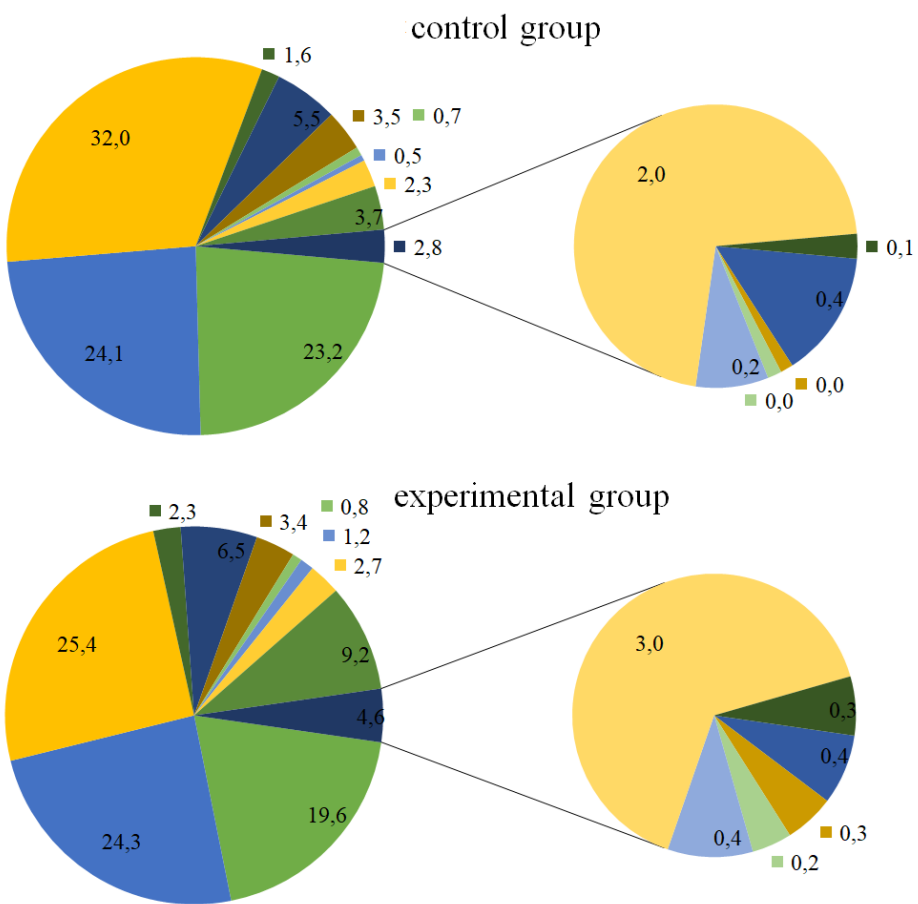

Fig. 10 Behavior of long-tailed chinchilla females during the day, \%. sleep

nap

rest

nibbling the cage mesh

- feed intake

a autocoprophagia

- water intake

grooming partner

grooming

- moving around the cage

- gnawing on a wooden shelf

a communication with each other

- sipping

w scratching

gnawing a block of wood

a communication with the chinchillas of the neighboring cage
- sleep

nap

rest

nibbling the cage mesh

- feed intake

autocoprophagia

water intake

grooming partner

grooming

noving around the cage

gnawing on a wooden shelf

communication with each other

- sipping

scratching

gnawing a block of wood

n communication with the chinchillas of the neighboring cage 


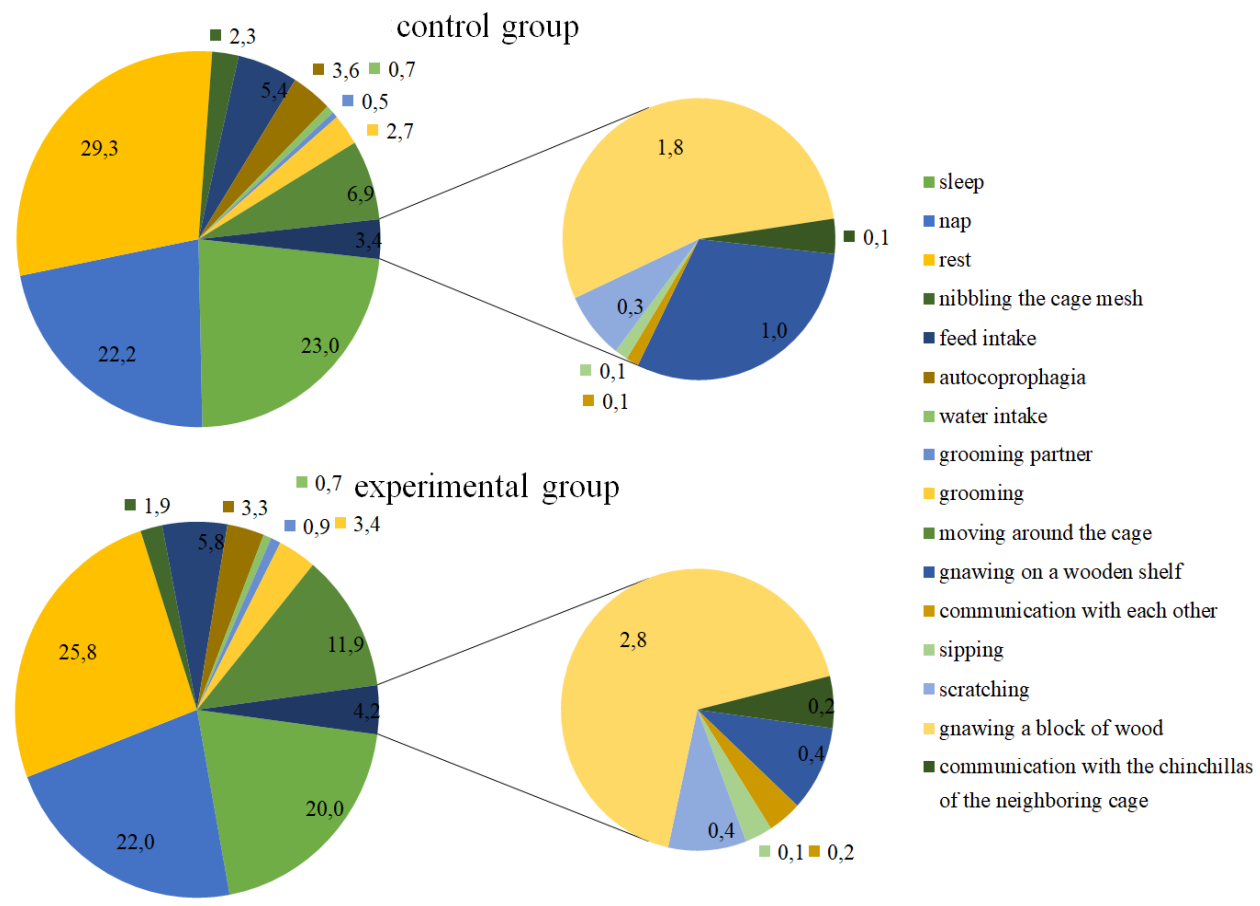

Fig. 11 Balance of diurnal behavior of a long-tailed chinchilla, \%.

\section{Conclusion}

As a result of an experimental study, we found that the inclusion of water enriched with molecular hydrogen in the diet of a small long-tailed chinchilla in the experimental group increased the total activity in males by $10 \%$, and in females by $33 \%(\mathrm{p}<0.05)$, compared with animals control group. The greatest difference among active forms of behavior was observed in the form of "moving around the cage." In the daytime, the males of the experimental group spent $55 \%$ more time on moving around the cage than the males of the control group, and in the females of the experimental group this indicator was $59 \%$ higher than that of the females of the control group. During the day, on average, in the experimental group, the activity of moving in the cage was $56 \%$ higher $(\mathrm{p}<0.05)$ compared with the control group.

\section{References}

1. P. Valladares, M. Espinosa, M. Torres, E. Diaz, N. Zeller, J. de La Riva, M. Grimberg, A. Spotorno. Mastozool. Neotrop 19, 173-178 (2012)

2. M. Novikov. Veterinary medicine, Zootechnics and Biology 2, 23-32 (2015)

3. R. Głogowski, D. Dzierżanowska-Góryń, K. Rak. SGGW. Anim. Sci. 52, 23-28 (2013)

4. J. Lanszki, Scientifur 23, 267-270 (1999)

5. Ö. Poyraz, Z. Akinci, E. Onbaşilar, J. Vet. Anim. Sci 29, 381-384 (2005)

6. P. Wolf, A. Schröder, A. Wenger, J. Kamphues. J. Anim. Physiol. Anim. Nutr, 87, 129-133 (2003) 
7. E. Panina, A. Ivanov, D. Petrov. Rabbit breeding and animal husbandry 2, 3-9 (2020)

8. E. Panina, A. Ivanov, D. Petrov. Reports of TSHA, 460-462 (2020)

9. E. Panina, A. Ivanov, D. Petrov, S. Panteleev. E3S Web of Conferences, 254, 08008 (2021)

10. G. Chupakhina, N. Chupakhina, P. Maslennikov et al. Publishing House, 191 (2019)

11. I. Bondarenko, O. Lysenko. Primorsky State Agricultural Academy, (2019)

12. B. Tikhonov, A. Sidorov, M. Sulman. Bulletin of Tver State University 1 (43), 23-29 (2021)

13. B. Mehrinigori, M. Ikromi, K. Mirzorakhimov. PAEMI DTT 4(43) (2020)

14. K. Melkonyan, T. Rusinova, Y. Kozmay, V. Nikonenko, N. Pisisskaya, A. Kozmay. Kuban State Medical University of the Ministry of Health of the Russian Federation, (2021)

15. L. Fan, H. Chen, J. Liang, D. Chen, Y. Huang. Applied Nanoscience 11, 833-840 (2021)

16. L. Yang, D. Li, S. Chen. Open Med 11(1), 399-406 (2016)

17. N. Jafta, S. Magagula, K. Lebelo, D. Nkokha, M. Mochane, First published 1 (2021)

18. J. Hancock, T. LeBaron, G. Russell. Species 11, (2021)

19. T. Ishibashi. Curr Pharm Des 19(35), 6375-81 (2013)

20. J. Fu, et al. Molecular Medicine Reports 18(6), 5009-5015 (2018)

21. S. Ohta, Biochim. Biophys. Acta Gen. Subj, 1820(5), 586-594 (2012)

22. H. Ono, Y. Nishijima, N. Adachi, M. Sakamoto, Y. Kudo, K. Kaneko, A. Nakao, T Imaoka. Med. Gas Res, 21 (2012)

23. J. Cui, Neuroscience 335, 232-241 (2016)

24. S. Ohta, Pharmacol. Ther 144, 1-11 (2014)

25. B. Kura, A. Bagchi, P. Singal, M. Barancik, T. LeBaron, K. Valachova, L. Šoltés, J. Slezák, J. Can. Physiol. Pharmacol 97(4), 287-292 (2019)

26. M. Henry, J. Chambron. Water 5(4), 2094-115 (2013)

27. M. Ichihara, S. Sobue, M. Ito, M. Ito, M. Hirayama, K. Ohno. Med. Gas Res 5, 1-21 (2015)

28. M. Dole, F. Wilson W. Fife. Science 190, 152-154 (1975)

29. I. Ohsawa, Nature medicine 13, 688-694 (2007)

30. C. Zhang, Y. Tang, X. Xu, S. Guo H. Wang, Experimental and therapeutic medicine 9, 2114-2120 (2015)

31. A. Shao, et al. Molecular neurobiology, 53, 3462-3476 (2015)

32. C. Wang, et al. Neuroscience letters, 491, 127-132 (2011)

33. K. Nagata, N. Nakashima-Kamimura, T. Mikami, I. Ohsawa, S. Ohta. Neuropsychopharmacology: ofcial publication of the American College of Neuropsychopharmacology, 34, 501-508 (2009)

34. Y. Suzuki, M. Sano, K. Hayashida, I. Ohsawa, S. Ohta, K. Fukuda. FEBS Lett, 583(13), 2157-2159 (2009)

35. T. Sato, S. Mimuro, T. Katoh, T. Kurita, S. Truong, K. Kobayashi, H. Makino, M. Doi, Y. Nakajima. J. Anesth, 1-8 (2020)

36. H. Oharazawa, T. Igarashi, T. Yokota, H. Fujii, H. Suzuki, M. Machide, H. Takahashi, S. Ohta, I. Ohsawa. Vis. Sci 51, 487-492 (2010) 
37. K. Hayashida, M. Sano, I. Ohsawa, K. Shinmura, K. Tamaki, K. Kimura, J. Endo, T. Katayama, A. Kawamura, S. Kohsaka, Biochem. Biophys. Res. Commun 373, 30-35 (2008)

38. Y. Zhang, J. Xu, Z. Long, C. Wang, L. Wang, P. Sun, P. Li, T. Wang, Front. Pharmacol 7, 1-12 (2016)

39. J. Cardinal, J. Zhan, Y. Wang, R. Sugimoto, A. Tsung, K. McCurry, T. Billiar, A. Nakao. Kidney Int 77, 101-109 (2010)

40. T. LeBaron, A. Larson, S. Ohta, T. Mikami, J. Barlow, J. Bulloch, M. DeBeliso. J. Lifestyle Med 9(1), 36-43 (2019)

41. M. Ito, M. Hirayama, K. Yamai, S. Goto, M. Ito, M. Ichihara, K. Ohno. Med. Gas Res, 15 (2012)

42. M. Ichihara, S. Sobue, M. Ito, M. Ito, M. Hirayama, K. Ohno. Med. Gas Res 5, 1-21 (2015)

43. M. Hirayama, M. Ito, T. Minato, A. Yoritaka, T. LeBaron, K. Ohno. Med. Gas Res 8(4), 144-149 (2018)

44. A. Tamasawa, K. Mochizuki, N. Hariya, M. Saito, H. Ishida, S. Doguchi, S. Yanagiya, T. Osonoi. J. Pharmacol 762, 96-101 (2015)

45. L. Qian, J. Shen, Y. Chuai et al. J. Biol Sci 9, 887-894 (2013)

46. M. Baeeri, S. Mohammadi-Nejad, M. Rahimifard et al. Mol Cell Biochem 441, 21-33 (2018)

47. P. Zhou, B. Lin, P. Wang et al. J. Radiat Res 60, 17-22 (2019)

48. L. Hong, Y. Yaru, L. Jing, L. Binghui, W. Huimin, Y. Luxun, W. Weidong, L. Rong. J. Radiat Res 62(1), 34-45 (2021) 